\title{
Beta-Adrenergic Blockers' Supportive and Adverse Role in Hypertension: A Review of Three Generations
}

\section{Zakir Khan', Elif Demirtaş', Olcay Kıroğlu', Yusuf Karataş',2}

'Institute of Health Sciences, Faculty of Medicine, Department of Pharmacology, Cukurova University, Adana, Turkey, ${ }^{2}$ Pharmacovigilance specialist, Balcali hospital, Faculty of Medicines, Cukurova University, Adana, Turkey.

\begin{abstract}
Hypertension causes significant mortality and morbidity around the world. The $\beta$-adrenergic blockers are one of the most commonly prescribed hypertension medications. Several $\beta$-adrenergic blockers with different pharmacological qualities have been developed, which may be grouped into three generations based on the differences in pharmacological properties. In this narrative review, we addressed evidence-based literature about the role of various types of $\beta$-blockers and related adverse drug reactions (ADRs) in hypertension. PubMed, Scopus, Google Scholar, and MEDLINE are used for articles search. The title was examined first, followed by the abstract, and then the entire study. We concluded that the first-generation $\beta$-blockers are non-selective and used as antihypertensive however, not recommended for diabetic, asthmatic, and chronic obstructive pulmonary disease patients. The second-generation $\beta$-blockers are $\beta 1$ receptor-selective which are the effective pharmacological option for the treatment of hypertension, with a lower risk of adverse effects associated with antagonism of $\beta$ 2 -receptor. Third-generation $\beta$-blockers showed improved effects on patients as compared to the previous two generations. This class of $\beta$-blockers (labetalol, carvedilol, and nebivolol) has vasodilatory abilities and has an extra beneficial influence with fewer ADRs. However, the effectiveness and benefit of $\beta$-blockers as first-line therapy for hypertension is still controversial. As a result, further accurate screenings, as well as large randomized control clinical trials (RCTs), are needed to investigate the role of all $\beta$-blockers in hypertension.
\end{abstract}

Keywords: Hypertension; Beta-Adrenergic Blockers; Blood Pressure; Literature Review.

\section{Corresponding Author: \\ Dr. Zakir Khan}

Institute of Health Sciences,

Faculty of Medicine, Department of Pharmacology,

Cukurova University, Adana, Turkey.

Email: zakirkhan300@gmail.com

https://doi.org/10.36283/PJMD11-1/011

How to cite: Khan Z, Demirtaş E, Kıroğlu O, Karataş Y. Beta-Adrenergic Blockers' Supportive and Adverse Role in Hypertension: A Review of Three Generations. 2022;11 (1): 63-71. doi: 10.36283/PJMD11-1/011

\section{INTRODUCTION}

Hypertension, often known as high or rising blood pressure (BP), is a condition in which the pressure in the arteries remains higher for a long time'. According to the World Health Organization (WHO) global- ly, hypertension affects an estimated 1.13 billion individuals with the majority living in low- and middle-income countries (LMICs). Furthermore, one out of every four males and one out of every five women is reported to have excessive higher $\mathrm{BP}^{2}$. 
Hypertension is a widespread condition that causes significant mortality and morbidity around the world ${ }^{3}$.

$\beta$-adrenergic blockers are one of the most prescribed commonly as hypertension medications ${ }^{4}$. More than a dozen novel $\beta$-adrenergic blockers for the treatment of hypertension have been launched since the availability of propranolol in 1976. Several $\beta$-adrenergic blockers with different pharmacological qualities have been developed, which may be grouped into three generations based on the differences in pharmacological properties $^{4}$. $\beta$-adrenergic antagonists block the endogenous catecholamines (epinephrine/adrenaline, norepinephrine/noradrenaline, and dopamine) on $\beta$-adrenergic receptors in the sympathetic nervous system and thus mediating the fight-or-flight response ${ }^{5}$.

$\beta$-adrenergic blockers were the first-line treatment for hypertension because they were well tolerated and provide effective management for exertion or stress-induced hypertension. However, a steppedcare approach is still commonly advocated in the management of hypertension. Therefore, patients whose BP is not managed satisfactorily by a $\beta$-adrenergic blocker are likely to be prescribed alternative antihypertensive medications ${ }^{6}$. Additionally, antihypertensive medications, particularly $\beta$-adrenergic blockers, are a troublesome medication class for hypertension therapy?.

According to a previous systematic review article, $\beta$-adrenergic blockers should not be used as 1st-line therapy for hypertension because they have a minimal effect on stroke and no significant reduction in mortality or coronary heart disease when compared to placebo. Moreover, $\beta$-adrenergic blockers were ineffective in reducing mortality and morbidity when compared to other medications (diuretics, renin-angiotensin inhibitors, and calcium channel blockers) ${ }^{8}$. It is also believed that $\beta$-adrenergic blockers in older persons (over 60 years of age) may not be justifiable due to physiologic changes such as bradycardia, low cardiac output, increase total peripheral resistance, reduced renal blood flow, low plasma renin activity, and decreased glomerular filtration rate? ${ }^{9}$ The effectiveness and benefit of $\beta$-blockers as first-line therapy for hypertension is still controversial. Therefore, continved exploration of clinical effects and safety-related research literature of $\beta$-blockers are critical for improving hypertension pharmacotherapy. However, there is no inclusive review of literature related to the role and safety of all $\beta$-blockers in hypertension.

\section{DISCUSSION}

In this narrative review, we addressed evidencebased literature about the role of various types of $\beta$ - adrenergic blockers and related adverse drug reactions (ADRs) in hypertension. The following keywords " $\beta$-blockers", " $\beta$-adrenergic receptor", " $\beta$ 1-adrenergic receptor antagonist", " $\beta 2$-adrenergic receptor antagonist" "first generation", "second generation", "third-generation", "extra ß1-effect", "hypertension" "selectivity" and "adverse drug reactions" were used to search PubMed, Scopus, Google Scholar, and MEDLINE for articles. There was no restriction for the date of publication and article types. The list of papers was then subsequently narrowed down to those containing abstracts and published in English. The title was examined first, followed by the abstract, and then the entire study.

\section{$\beta$ - adrenergic receptors and mechanism of action}

$\beta 1$ and $\beta 2$ receptors are the most prevalent adrenergic receptors found in human cardiovascular tissues. The heart and kidneys have most $\beta 1$-adrenergic receptors while the gastrointestinal tract, liver, lungs, uterus, vascular smooth muscle, and skeletal muscle have $\beta 2$-receptors ${ }^{5,6}$. The $\beta 1$ and $\beta 2$ receptor agonists are individually linked to the activation of adenylyl cyclase and the production of cyclic adenosine monophosphate (CAMP) via their interaction with the heterotrimer G-protein GS alpha. Adenylyl cyclase starts a CAMP-dependent pathway signaling $G$ s, which leads to potentiation of the receptor's action ${ }^{10}$. Targeted stimulation of the $\beta 1$ receptor in the heart increases heart rate and contractility by boosting sinoatrial (SA) nodal, atrioventricular (AV) nodal, and ventricular muscle firing. The stroke volume and cardiac output will also increase as these two variables rise. Cardiac output is calculated as the sum of stroke volume and heart rate. As stroke volume or heart rate rises as a result of targeted $\beta 1$ receptor activation, cardiac output will also increase and ultimately be responsible for the increasing perfusion to tissues throughout the body. The smooth muscle cells in the juxtaglomerular apparatus of the kidney contract and release renin due to $\beta 1$ receptor activation. This effect will ultimately raise blood volume due to the angiotensin II and aldosterone action ${ }^{11}$.

\section{$\boldsymbol{\beta}$-adrenergic blockers classification}

$\beta$ blockers differ in terms of $\beta 1 / \beta 2$-adrenergic receptor selectivity and vasodilatory activity, which has led to their classification as first-, second-, and third-generation agents. First-generation $\beta$-blockers (propranolol, pindolol, etc.) are termed as non-selective because they exert equal blockade of $\beta 1$ - and $\beta 2$-receptors. The second-generation beta-blockers (such as atenolol, metoprolol, bisoprolol, betaxolol, acebutolol, etc.) are referred to as selective because they have a higher affinity for $\beta 1$ - than $\beta 2$-adrenergic receptors. Finally, vasodilatory properties distinguish third-generation $\beta$-blockers (labetalol, carvedilol, nebivolol, etc.) from first- and second-generation $\beta$-blockers. This class of $\beta$ blockers has varying selectivity for $\beta$ 1-recep- 
tors and acts as a vasodilator by blocking a l-adrenoreceptors and activating 33 -adrenergic receptors. This class is the most effective for lowering blood pressure. The detailed properties of different $\beta$-blockers are listed in Table 1.

Table 1: Properties of first, second, and third-generation $\beta$-blockers.

\begin{tabular}{|c|c|c|c|c|c|c|c|}
\hline Class & Selectivity & Vasodilation & $\begin{array}{c}\text { Lipid } \\
\text { solubility }\end{array}$ & *ISA & ${ }^{* *}$ MSA & $\begin{array}{l}{ }^{* * *} \alpha \text { blocking } \\
\text { activity }\end{array}$ & Excretion \\
\hline \multicolumn{8}{|c|}{$1^{\text {st }}$ generation } \\
\hline Propranolol & Non-Selective & No & Yes & No & Yes & No & Hepatic \\
\hline Pindolol & - & No & Yes & Yes & Yes & No & Hepatic \\
\hline \multicolumn{8}{|c|}{$2^{\text {nd }}$ generation } \\
\hline Atenolol & $\beta 1$-selective & No & Low & No & No & No & Renal \\
\hline Metoprolol & - & No & Yes & No & Yes & No & Hepatic \\
\hline Bisoprolol & - & No & Low & No & No & No & $\begin{array}{l}\text { Renal/ } \\
\text { Hepatic }\end{array}$ \\
\hline Betaxolol & - & & Yes & No & Yes & No & $\begin{array}{l}\text { Renal/ } \\
\text { Hepatic }\end{array}$ \\
\hline Acebutolol & - & No & No & Yes & Yes & No & Bile/Renal \\
\hline Celiprolol & - & Mild & Low & Yes & No & No & Renal \\
\hline Practolol & - & No & No & Yes & low & No & Renal \\
\hline \multicolumn{8}{|c|}{$3^{\text {rd }}$ generation } \\
\hline Labetalol & $\begin{array}{c}\text { Non-selective } \beta \text {-blocker and } \\
\text { selective, a l-adrenergic } \\
\text { antagonist }\end{array}$ & Yes & Yes & Yes & Yes & Yes & Bile/Renal \\
\hline Carvedilol & $\begin{array}{c}\text { Non-selective } \beta \text {-blocker and } \\
\text { a l-adrenergic antagonist }\end{array}$ & Yes & Yes & No & Yes & Yes & Hepatic \\
\hline Nebivolol & $\begin{array}{c}\beta 1 \text {-selective antagonist and } \beta 3 \\
\text { agonist }\end{array}$ & Yes & Yes & No & No & Yes & Bile/Renal \\
\hline
\end{tabular}

*ISA = Intrinsic sympathomimetics activity, ${ }^{* *} \mathrm{MSA}=$ Membrane stabilizing activity, ${ }^{* * *} \alpha=\mathrm{Alpha}$.

First-generation $\beta$-blockers nonselective $\beta$-blockers: Propranolol

Propranolol was the first developed b-blocker used in clinical practice in 1964. Propranolol is a lipophilic substance that can cross the blood-brain barrier. It has good absorption when taken orally, however, it is subject to the first-pass metabolism, with only $25 \%$ of the medication reaching the systemic circulation. Propranolol has a large volume of (near $4 \mathrm{~L} / \mathrm{kg}$ ), 90\% plasma protein binding, and a short half-life (3-6 hours) ${ }^{10,11}$. Propranolol reduces systolic and diastolic $\mathrm{BP}$, as well as cardiac output and renin-angiotensin system activity ${ }^{11}$.

Propranolol's antihypertensive effect on diastolic and systolic blood pressure has been described in prior studies ${ }^{12}$. It is found that two or four daily dosages of propranolol (160-320 mg) were effective in lowering blood pressure in hypertensive patients to normal values ${ }^{12}$. According to the recent review, propranolol has emerged as a valuable tool for clinicians in the cost-effective treatment of hypertension. Propranolol does not cause postural or exercise hypotension, and it appears to be more patient-friendly than other medications. The best management of supine blood pressure is usually achieved with propranolol ${ }^{13}$.

The non-selective $\beta$-adrenergic antagonism of propranolol can induce major adverse effects, such as bronchospasm in people with asthma or chronic obstructive pulmonary disease, which are linked to $\beta$ 2-receptor antagonism. Furthermore, due to $\beta 2$ antagonism on the peripheral vasculature, propranolol may raise peripheral vascular resistance ${ }^{10,13}$. However, more propranolol comparison trials are needed to determine the effect and safety in different populations.

\section{Pindolol}

Pindolol is a $\beta$-adrenergic blocker that has equally potent activity on $\beta$ I- and $\beta 2$ adrenoceptors and 
holds partial agonist activity. It has a high systemic availability due to its minimal first-pass effect. Pindolol's duration of action is longer than propranolol's. Pindolol is quickly and completely absorbed and after 1.5 to 2 hours reaches its maximum plasma level. It has a half-life of 3-4 hours, and $40 \%$ of the medication is excreted unaltered in the urine ${ }^{14}$.

Pindolol is commonly given twice or three times a day in the treatment of hypertension. However, it is also reported that the $\beta$-blocking action of a single oral dose of $10 \mathrm{mg}$ pindolol has been observed to last for 24 hours $^{15}$. According to a previously published review which evaluates several hundred clinical trials performed in many countries reported that $\mathrm{BP}$ reductions achieved with pindolol were not statistically different from those achieved with other beta-blockers, whether cardio-selective (metoprolol, atenolol) or not (propranolol, timolol, nadolol). Pindolol slowed the resting heart rate less than the other five medications. Pindolol caused less bradycardia than propranolol ${ }^{16}$.

Although pindolol is as effective as propranolol in the treatment of hypertension, however, it is reported that central nervous system adverse effects were more frequent with pindolol. A "ceiling effect" may occur as dosages are increased above 20 to $30 \mathrm{mg} /$ day, which means that further BP decreases may not be possible. Some individuals will experience a paradoxical increase in BP with an increase in dose ${ }^{17}$.

\section{The second-generation $\beta$-blockers Selective $\beta-1$ blockers: Atenolol}

Atenolol is a second-generation $\beta 1$-selective adrenergic antagonist used to treat hypertension. Atenolol was developed in 1973. Atenolol is a hydrophilic medication with a $50 \%$ absorption rate. It has a half-life of 5-8 hours and is predominantly removed via the renal route without any biotransformation" ${ }^{1}$. Atenolol binds to $\beta-1$ adrenergic receptors in vascular smooth muscle and the heart and inhibiting the positive inotropic and chronotropic effects of endogenous catecholamines (isoproterenol, norepinephrine, and epinephrine), and thus block the sympathetic stimulation. Heart rate, BP, and cardiac contractility decrease due to this activity ${ }^{18}$.

Atenolol is one of the most frequently used $\beta$-blockers in clinical practice, and it is frequently employed as a reference medication in hypertension randomized controlled trials ${ }^{19}$. Previous research has shown that atenolol, either alone or in combination with other antihypertensive medications is effective in the treatment of hypertension ${ }^{18}$. A recently published metaanalysis revealed that the weaker ability of non-vasodilation $\beta$-blockers (mostly atenolol) to reduce central vs peripheral systolic blood pressure occurred mostly from heart rate reduction ${ }^{19}$. According to a meta-analysis of five trials $(17,671$ participants) comparing atenolol to other antihypertensive drugs, atenolol has, similar efficacy to the other drugs in terms of lowering BP, but there was significantly higher mortality in the atenolol group for the 4.6-year follow-up period. Importantly, the atenolol group had also a higher risk of cardiovascular death and stroke ${ }^{20}$.

Furthermore, a recent randomized controlled study revealed that bisoprolol might have an improved effect on central aortic pressure than atenolol ${ }^{21}$. According to an Indian study conducted among 440 hypertensive patients, atenolol induced cold extremities (1.18\%), headache and dizziness (1.41\%), dyspnea $(0.94 \%)$, edema $(0.70 \%)$, and bradycardia $(0.47 \%)^{22}$. Additionally, an Ethiopian study conducted at an ambulatory clinic in a tertiary care hospital showed observed patients with atenolol therapy experienced swollen feet/legs and cold hands/feet as an adverse effect ${ }^{23}$. According to Carlberg et al., the suitability and efficacy of atenolol as an antihypertensive medication is presently debatable and its use as a reference drug in antihypertensive therapy trials might no longer be appropriate ${ }^{20}$.

\section{Metoprolol}

Metoprolol, second-generation $\beta$-blockers was introduced in 1973. Metoprolol is a non-vasodilating $\beta-1$ adrenergic antagonist licensed by the Food and Drug Administration (FDA) for hypertension. Lipophilicity, high absorption rate, widespread first-pass metabolism, and a half-life of 3 to 4 hours are the key pharmacokinetic features of metopro$\mathrm{Iol}^{24}$. A randomized trial found that metoprolol improved endothelial function and carotid artery flexibility while also lowering BP in mildly hypertensive subjects ${ }^{25}$. It is reported that the animals' blood pressure reduced after the administration of oral metoprolol $(0.7 \mathrm{mmol} / \mathrm{kg})$ administration for 5-months. A similar effect was also observed with intravenous $(15 \mu \mathrm{mol} / \mathrm{kg})$ administration of metoprolol for four days ${ }^{26}$.

An antihypertensive effect has also been seen in hypertensive individuals treated with metoprolol (25-200 mg). Metoprolol reduced both systolic and diastolic BP to normal levels after six months of treatment, with no change in left ventricular mass. These findings revealed an antihypertensive effect of metoprolol without an antihypertrophic outcome. However, on the other hand, metoprolol-treated patients were more likely to feel fatigued, increased perspiration, and have sleep difficulties. Furthermore, greater doses of metoprolol have a higher risk of causing adverse effects ${ }^{27}$.

\section{Bisoprolol}

Bisoprolol is an effective and safe antihypertensive drug due to its strong $\beta 1$-selectivity, long duration of action, and favorable pharmacokinetic features ${ }^{21}$. 
Bisoprolol is a low lipophilic drug with a long half-life $(9$ to 12 hours) and high bioavailability $(80 \%)$ compared to most $\beta$-blockers, which have reduced bioavailability due to significant first-pass metabolism ${ }^{28}$.

Bisoprolol, like other $\beta 1$-blockers, has a negative inotropic and chronotropic effect, which means it reduces heart rate and force of contractions. Bisoprolol also lowers myocardial cell oxygen consumption ${ }^{21,28}$. Bisoprolol has been extensively studied for the treatment of essential hypertension all over the world $^{29}$. FDA approved bisoprolol for hypertension therapy ${ }^{10}$. According to a multicentric observational study, bisoprolol can be utilized as a first-line treatment for people with stage I essential hypertension. Bradycardia is a commonly reported adverse effect of bisoprolol due to its negative chronotropic and inotropic effects ${ }^{29}$.

\section{Betaxolol}

Betaxolol is a strong long-acting $\beta$ 1-selective adrenergic blocker ${ }^{30}$. It has a minimal membrane-stabilizing (local anesthetic) effect and no partial agonist (intrinsic sympathomimetic) activity ${ }^{30}$. According to the FDA, topical betaxolol is indicated for patients with ocular hypertension and chronic open-angle glaucoma. The FDA has approved its use to treat essential hypertension in its systemic form ${ }^{31}$. The bioavailability of betaxolol after oral administration ranges from 80 to $89 \%$ and is unaffected by the presence of food in the gut. Betaxolol is distributed in several places, including the placenta and milk. It is converted primarily into inactive metabolites and excreted through urine; however, some unaltered drug (about $15 \%$ of a dose) is also excreted. It has a long half-life ( 14 to 22 hours), which is prolonged by severe renal impairment but not by hepatic failure ${ }^{31}$. Its half-life is also longer in older people and newborn babies. Otherwise, its pharmacokinetic behavior in infants and adults is nearly the same ${ }^{32}$.

Betaxolol single oral dose (10 to $20 \mathrm{mg}$ per day) is advised as a starting dose for mild to severe hypertension. Betaxolol's antihypertensive effect has been studied in several trials. These studies reported that $20 \mathrm{mg}$ daily dose was found to be the most effective in most people with mild hypertension ${ }^{32}$. Most patients have responded favorably to betaxolol, but long-term experience (greater than a year) is limited to a small number of patients. A few cases of severe bradycardia have been reported mostly in elderly individuals or those given a higher dose (40 mg/day). Bronchoconstriction has only been recorded in rare cases. The most typically reported adverse reactions were mild central symptoms such as fatigue and headaches ${ }^{30}$.

\section{Acebutolol}

Acebutolol, a cardio-selective $\beta$ 1-receptor blocker with some intrinsic sympathomimetic activity (ISA) and has been demonstrated to be useful in treating hypertension ${ }^{33}$. Acebutolol is quickly absorbed and has a long terminal half-life (8-1 $1 \mathrm{~h})$. It is revealed that acebutolol appeared to be both a safe and effective antihypertensive drug than a placebo ${ }^{33}$.

Acebutolol is effective in the treatment of mild to moderately severe essential hypertension, and it is better tolerated than propranolol in terms of central nervous system (CNS) adverse effects with a much-reduced effect on heart rate ${ }^{34}$. Once-daily acebutolol as monotherapy is claimed to give effective control in a vast majority of people with mild to moderate essential hypertension, and when administered in conjunction with diuretics results in a further reduction in BP. Acebutolol, on the other hand, has documented side effects include dizziness, headache, fatigue, and gastrointestinal distress, which are also common with all $\beta$ blockers $^{35}$.

\section{Celiprolol}

Celiprolol is a second-generation $\beta 1$-adrenoceptor antagonist with partial $\beta 2$ agonist action. It has an antihypertensive activity like other blockers, but it lacks the typical adverse effects (bronchoconstriction, left ventricular function depression, and peripheral vasoconstriction) of the class due to its $\beta$ 2 agonist action ${ }^{36}$. It is documented that celiprolol decreases arteriolar resistance and enhances blood flow without impairing the heart function ${ }^{37}$. A single (400-mg) oral dose lowered standing diastolic $\mathrm{BP}$ by around $10 \%$ in healthy people while having little effect on systolic BP. When compared to propranolol, celiprolol does not produce clinically significant bradycardia, and it causes less dizziness, fatigue, and tiredness than atenolol which indicates its better tolerability profile ${ }^{38}$. Patients with cardiogenic shock, second- or third-degree heart blockage, severe bradycardia, and decompensated heart failure should not be used celiprolol ${ }^{38}$.

Celiprolol has been proven in multiple studies to not affect respiratory activity in chronic obstructive pulmonary disease or asthmatic patients ${ }^{39}$. However, there have been reports of asthma and bronchospasm in individuals using celiprolol ${ }^{38}$, as well as a case of hypersensitivity pneumonitis that recurred after the medicine was reintroduced ${ }^{40}$. As a result, celiprolol should be used with caution in individuals with lung disease, and respiratory symptoms monitoring is still suggested in adults without lung illness ${ }^{37}$.

\section{Practolol}

Practolol, a second-generation $\beta$-adrenergic blocker introduced in 1968. Practolol inhibits the actions of the catecholamines epinephrine and norepinephrine by binding to $\beta 1$-adrenergic receptors, lowering heart rate, cardiac output, and systolic and diastolic BP. Practolol is unique in that it is almost fully removed by 
renal elimination primarily through glomerular filtration with a half-life of 9-12 hours ${ }^{41}$.

Antihypertensive effects of practolol were studied in previous studies, and it was observed that practolol had a good and nearly equal antihypertensive effect as other $\beta 1$-selective blockers ${ }^{42}$. However, oculomucocutaneous syndrome, which affects the skin, eyes, oral and nasal mucous membranes, ears, and the peritoneum is the most common adverse reaction linked with practolol. Muscle cramps, heart failure, bradycardia, hypotension, and bronchospasm were all reported with practolol therapy. As a result, practolol is no longer available in some countries, and its usage is restricted in others ${ }^{43}$.

\section{Third generation $\boldsymbol{\beta}$-blockers: Labetalol}

Kennedy and Levy verified in 1975 that labetalol is the first representative of the third generation $\beta$-blockers, which inhibited isoprenaline-induced increases in contractile force, and heart rate. Furthermore, labetalol ( $3 \mathrm{mg} / \mathrm{kg}$ ) was found to reduce the hypertensive effect of noradrenaline in vivo ${ }^{44}$. Labetalol also has a $\beta$-adrenergic antagonist effect in addition to al-adrenergic antagonism. In terms of pharmacokinetic properties, labetalol is a medication with a rapid absorption rate, an extensive first-pass metabolism, and a half-life of 3 to 8 hours ${ }^{11}$. Labetalol is absorbed after oral administration with a wide range of bioavailability (11-86\%) and peak plasma levels were reported in hypertensive individuals after administration of 100 and 200 mg dosages ${ }^{45}$.

Labetalol is an antihypertensive drug that can be used orally or intravenously. Labetalol hydrochloride is an injectable antihypertensive medication approved by the $\mathrm{FDA}^{46}$. A randomized control trial revealed that labetalol control BP (mean systolic and diastolic BP) in pregnant women with chronic hypertension ${ }^{47}$. According to a recent study, labetalol reduced arterial blood pressure in dogs with a non-significant increase in heart rate as a therapy for perioperative non-nociceptive acute hypertension ${ }^{48}$.

Several studies on labetalol treatment in large groups of people examined the nature and frequency of adverse effects. Nausea, vomiting, stomach discomfort, diarrhea, and constipation are among the non-specific gastrointestinal side effects reported by up to $15 \%$ of the patients ${ }^{49}$. Tiredness, headaches, and skin rashes are some of the less commonly reported non-specific adverse effects. The most troublesome adverse effect of labetalol medication is posture-related dizziness, which affects roughly $5 \%$ of patients and is caused by an a-adrenoceptor blockade. It occurs more frequently in the early phases of treatment and when the medicine is given in higher doses ${ }^{50}$. Asthma, muscle spasms, heart failure, and symptoms of a vivid dream are uncommon (frequency of $3 \%$ or less) side effects associated with labetalol's $\beta$-adrenoceptor blocking action. $\beta$ adrenoceptor blockade side effects are often less troublesome with labetalol than pure $\beta$-adrenoceptor blockers ${ }^{45}$.

\section{Carvedilol}

Carvedilol is a non-selective third-generation $\beta$-blocker that also inhibits al-adrenergic receptors. Carvedilol is a unique, multi-action cardiovascular medication that has been approved for hypertension in several countries ${ }^{51}$. Carvedilol has a half-life of 7 to 10 hours in most people which necessitates its twice-daily administration. Carvedilol is a lipophilic medication with a high absorption rate that goes through extensive first-pass biotransformation ${ }^{10,11}$.

Meyer-Sabellek et al. administered two doses of carvedilol daily for twelve months or a single dose for six months to hypertensive patients and found that both systolic and diastolic BP were reduced to normal values. Carvedilol lowers BP within two hours after administration. This response was sustained for 24 hours and this characteristic was not observed in the first and second generations $\beta$-blockers ${ }^{52}$. Messerli and Grossman reported that the carvedilol a-blocking action may counterbalance some of the unfavorable chronotropic and inotropic effects associated with older $\beta$-blockers and may have a greater beneficial outcome on cardiovascular function in elderly patients ${ }^{53}$. Based on the current evidence, carvedilol could be a useful option tool in the clinicians' hands during the difficult task of hypertension management. Edema, bradycardia, nausea, diarrhea, dizziness, hypotension, and blurred vision were the most prevalent side effects observed with carvedilo ${ }^{54}$.

\section{Nebivolol}

Nebivolol is the latest third-generation $\beta$-blocker with a $\beta 1$ antagonistic effect and was first launched in $1988^{10}$. Nebivolol is highly $\beta 1$-selective at dosages of $10 \mathrm{mg} /$ day with a 320 -fold higher affinity for $\beta 1$ than $\beta 2$ receptors in human myocardial cells. Nebivolol is a well-absorbed medication that undergoes extensive first-pass biotransformation. Its half-life is around 12 hours but is prolonged to $19 \mathrm{~h}$ in poor metabolizer populations, and it is mostly eliminated by feces (44\%) and urine (37\%) "'. Nebivolol was found to lower BP in hypertensive rats at lower doses than propranolol and atenolol. It increases nitric oxide-induced vasodilation by triggering endothelial nitric oxide synthase through $\beta 3$ agonism. This process differs from that of other vasodilatory $\beta$-blockers (carvedilol, labetalol), which work by blocking a-adrenergic receptors. In the United States, nebivolol is permitted for hypertension treatment, while in Europe, it is licensed for hypertension and heart failure ${ }^{55}$. 
Several clinical investigations with different doses (ranging from 5 to $40 \mathrm{mg} /$ day) have examined its antihypertensive impact based on its pharmacological properties. Both systolic and diastolic BP was reduced in these studies, confirming its antihypertensive action ${ }^{56}$. In hypertensive rats, Ceron et al. examined the nebivolol and metoprolol effects and reported that both $\beta$-adrenergic antagonists were antihypertensive, but only nebivolol produced antihypertrophic effects in the aortic tissue, as well as systemic and vascular antioxidant benefits. Neither of these effects was found after therapy with metoprolo| ${ }^{57}$. Age does not affect the pharmacokinetics of nebivolol. However, for people over the age of 65 , the suggested starting dose is $2.5 \mathrm{mg}$ per day. This is following the fact that many other antihypertensive medications are reduced in dose for elderly individuals. Nebivolol is also effective in lowering cardiovascular illness and death in older individuals with heart failure ${ }^{58}$. According to Coats and Jain, nebivolol is a promising antihypertensive medication with excellent antioxidative characteristics due to its ability to release nitric oxide ${ }^{59}$.

It has demonstrated significant efficacy and safety in lowering BP and avoiding organ damage, as well as its ability to act as an effective disease-modifying agent in elderly heart failure patients regardless of left ventricular ejection fraction, making it a promising treatment choice for high-risk hypertension ${ }^{59}$. The rate of discontinuation owing to adverse events (AEs) among nebivolol-treated patients (all dosages) was reported to be low (2.6\%) and equivalent to placebo (2.0\%). The most prevalent AEs in nebivolol patients were headache $(7.1 \%$ vs. $5.9 \%$ for placebo), fatigue (3.6\% vs. 1.5 percent), and dizziness (2.9\% vs. 2.0 percent) ${ }^{55}$. According to the recent Korean study conducted among 3250 participants reported that nebivolol can be utilized to improve BP outcomes in hypertensive patients with and without comorbidities, either alone or in conjunction with other antihypertensive medications. Most side effects were mild such as dizziness (1.3\%), headache $(1.0 \%)$, and dyspnea $(0.9 \%){ }^{60}$.

\section{CONCLUSION}

First-generation $\beta$-blockers lower blood pressure by reducing the contractile strength and rate of the heart, which in turn lowers cardiac output. This action allows them to be used in hypertensive patients. On the other hand, first-generation $\beta$-blockers are not recommended for diabetic, asthmatic, and chronic obstructive pulmonary disease patients. The second-generation $\beta$-adrenergic antagonists have $\beta 1$-receptor selectivity. As a result, they play a role in lowering cardiac output and activation of the renin-angiotensin system and thus reducing blood pressure. Therefore, second-generation $\beta$-blockers are an effective pharmacological option for the treatment of hypertension, with a lower risk of adverse effects associated with antagonism of $\beta 2$-receptor. Third-generation $\beta$-blockers show improved effects on patients with cardiovascular disorders when compared to the representatives of the previous two generations. This class of $\beta$-blockers (labetalol, carvedilol, and nebivolol) has vasodilatory abilities and has an extra beneficial influence on metabolic and hemodynamic parameters, with fewer adverse effects. However, the effectiveness and benefit of $\beta$-blockers as first-line therapy for hypertension is still controversial.

\section{ACKNOWLEDGEMENTS}

The authors would like to acknowledge the institution for facilitating the study.

\section{CONFLICT OF INTEREST}

All the authors declared no conflict of interest.

\section{AUTHORS' CONTRIBUTION}

ZK wrote the manuscript, ED, OK, and YK revised and edited the manuscript.

\section{REFERENCES}

1. Zeng Z, Chen J, Xiao C, Chen W. A global view on prevalence of hypertension and human develop index. Ann Glob Health. 2020 ;86(1):1-6. doi: 10.5334/aogh.2591

2. World Health Organization (WHO). Hypertension [Internet]. 2019. Available at: https://www.who.int/news-room/fact-sheets/detail/hypertension

3. Mills KT, Stefanescu A, He J. The global epidemiology of hypertension. Nat Rev Nephrol. 2020;16(4):223-237. doi: 10.1038/s41581-019-0244-2

4. Larochelle $P$, Tobe SW, Lacourcière $Y$. $\beta$-Blockers in hypertension: studies and meta-analyses over the years. Can J Cardiol. 2014;30(5):16-22. doi: 10.1016/j .cjca.2014.02.012

5. Wiysonge CS, Volmink J, Opie LH. Beta-blockers and the treatment of hypertension: it is time to move on. Cardiovasc J Afr. 2007;18(6):351-352.

6. Weber MA. The role of the new beta-blockers in treating cardiovascular disease. Am J Hypertens. 2005;18(1):169-176. doi: 10.1016/j.amjhyper.2005 .09 .009

7. Vögele A, Johansson T, Renom-Guiteras A, Reeves $D$, Rieckert A, Schlender $L$, et al. Effectiveness and safety of beta blockers in the management of hypertension in older adults: a systematic review to help reduce inappropriate prescribing. BMC Geriatr. 2017;17(1):119-143. doi: doi.org/10.1186/s12877-0170575-4

8. Wiysonge CS, Bradley HA, Volmink J, Mayosi BM, Opie $\mathrm{LH}$. Beta-blockers for hypertension. Cochrane Database Syst Rev. 2017(1):1-74. doi: 10.1002/14651858.CD002003.pub5

9. Messerli FH. The age factor in hypertension. Hosp Pract. 1986;21(1):103-112. doi: 10.1080/21548331.1 
986.11706552

10. do Vale GT, Ceron CS, Gonzaga NA, Simplicio JA, Padovan JC. Three generations of $\beta$-blockers: history, class differences and clinical applicability. Curr Hypertens Rev. 2019;15(1):22-31. doi: 10.2174/ 1573402114666180918102735

11. Reiter MJ. Cardiovascular drug class: Beta-blockers. Prog Cardiovasc Dis. 2004; 47(1):11-33. doi: 10.1016/j.pcad.2004.04.004

12. Hansson L, Zweifer AJ. The effect of propranolol on plasma renin activity and blood pressure in mild essential hypertension. Acta Med Scand. 1974; 195(1-6):397-401. doi: 10.1111/j.0954-6820.1974. tb08159.x

13. Srinivasan AV. Propranolol: A 50-year historical perspective. Ann Indian Acad Neurol. 2019;22(1):21-26. doi:10.4103/aian.AIAN_201_18

14. McDevitt DG. Comparison of pharmacokinetic properties of beta-adrenoceptor blocking drugs. Eur Heart J. 1987;8 Suppl M:9-14. doi: 10.1093/eurheartj/8.suppl_m.9

15. Frithz G. Pindolol once daily in the treatment of hypertension. Ups J Med Sci. 1976;81 (3):151-154. doi: 10.3109/03009737609179040

16. Fanchamps A. Therapeutic trials of pindolol in hypertension: comparison and combination with other drugs. Am Heart J. $1982 ; 104(2$ Pt 2):388-406. doi: 10.1016/0002-8703(82)90129-6

17. Golightly LK. Pindolol: a review of its pharmacology, pharmacokinetics, clinical uses, and adverse effects. Pharmacother J Hum Pharmacol Drug Ther. 1982;2(3):134-147. doi: 10.1002/j.1875-9114.1982.tb045 21.x

18. Heel RC, Brogden RN, Speight TM, Avery GS. Atenolol: a review of its pharmacological properties and therapeutic efficacy in angina pectoris and hypertension. Drugs. 1979;17(6):425-460. doi: 10.2165/00003495-197917060-00001

19. Pucci G, Ranalli MG, Battista F, Schillaci G. Effects of $\beta$-blockers with and without vasodilating properties on central blood pressure: systematic review and meta-analysis of randomized trials in hypertension. Hypertens. 2016;67(2):316-324. doi: 10.1161/HYPERTENSIONAHA.115.06467

20. Carlberg B, Samuelsson O, Lindholm LH. Atenolol in hypertension: is it a wise choice? Lancet. 2004;364(9446):1684-1689. doi: 10.1016/S0140- 6736 (04) $17355-8$

21. Zhou WJ, Wang RY, Li Y, Chen DR, Chen EZ, Zhu $\mathrm{DL}$, et al. A randomized controlled study on the effects of bisoprolol and atenolol on sympathetic nervous activity and central aortic pressure in patients with essential hypertension. PLOS One. 2013;8(9):1-8. doi: 10.1371/journal.pone.0072102 22. Garg KC, Singhal KC, Kumar S. Monitoring the adverse profile of atenolol--a collaborative study. Indian J Physiol Pharmacol. 1993;37(3):213-216.

23. Gebreyohannes EA, Bhagavathula AS, Abebe TB, Tefera YG, Abegaz TM. Adverse effects and non-adherence to antihypertensive medications in University of Gondar Comprehensive Specialized
Hospital. Clin Hypertens. 2019;25(1):1-9. doi: 10.1186/s40885-018-0104-6

24. Fröhlich H, Zhao J, Täger T, Cebola R, Schellberg D, Katus HA, et al. Carvedilol compared with metoprolol succinate in the treatment and prognosis of patients with stable chronic heart failure: carvedilol or metoprolol evaluation study. Circ Heart Fail. 2015;8(5):887-896. doi: 10.1161/CIRCHEARTFAILURE. 114.001701

25. Kosch $M$, Levers A, Lang D, Bartels $V$, Rahn $K H$, Pavenstädt $\mathrm{H}$, et al. A randomized, double-blind study of valsartan versus metoprolol on arterial distensibility and endothelial function in essential hypertension. Nephrol Dial Transplant. 2008;23(7):2280-2285. doi: 10.1093/ndt/gfm936

26. Ljung B, Ảblad B, Drews L, Fellenius E, Kjellstedt A, Wallborg M. Anti-hypertensive effect of metoprolol in spontaneously hypertensive rats. Clin Sci Mol Med. 1976;51 (s3):443-445. doi: 10.1042/cs051443s 27. Dahlöf C, Hedner T, Thulin T, Gustafsson S, Olsson SO. Effects of diltiazem and metoprolol on blood pressure, adverse symptoms and general well-being. The Swedish Diltiazem-Metoprolol Multi-Centre Study Group. Eur J Clin Pharmacol. 1991;40(5):453-460. doi: 10.1007/BF00315222

28. Galougahi KK, Liu CC, Bundgaard H, Rasmussen $\mathrm{HH}$. $\beta$-Adrenergic regulation of the cardiac $\mathrm{Na}+\mathrm{K}+$ ATPase mediated by oxidative signaling. Trends Cardiovasc Med. 2012;22(4):83-87. doi: 10.1016/j.tcm.2012.06.017

29. Channaraya V, Marya RK, Somasundaram M, Mitra $D$, Tibrewala KD; BRIGHT investigators. Efficacy and tolerability of a $\beta-1$ selective $\beta$ blocker, bisoprolol, as a first-line antihypertensive in Indian patients diagnosed with essential hypertension (BRIGHT): an open-label, multicentric observational study. BMJ Open. 2012;2(3):1-6. doi:10.1136/bmjopen-2011-000683

30. Beresford R, Heel RC. Betaxolol. A review of its pharmacodynamic and pharmacokinetic properties, and therapeutic efficacy in hypertension. Drugs. 1986;31 (1):6-28. doi: 10.2165/00003495-198631010-00002 31. Onishchenko AL, Isakov IN, Kolbasko AV, Makogon SI. Initial combination therapy for primary open-angle glaucoma. Vestn Oftalmol. 2019;135(2):32-38. doi: 10.17116/oftalma201913502132

32. Williams RL, Goyle KK, Herman TS, Rofman BA, Ruoff GE, Hogan LB. Dose-dependent effects of betaxolol in hypertension: a double-blind, multicenter study. J Clin Pharmacol. 1992;32(4):360-367. doi: 10.1002/j.1552-4604.1992.tb03848.x

33. Alhenc-Gelas F, Plouin PF, Ducrocq MB, Corvol P, Menard J. Comparison of the antihypertensive and hormonal effects of a cardioselective beta-blocker, acebutolol, and diuretics in essential hypertension. Am J Med. 1978;64(6):1005-1012. doi: 10.1016/0002-9343(78) 90456-4

34. Davidov M. Acebutolol in essential hypertension: results of two multicenter studies against placebo and propranolol. Am Heart J. 1985;109/5 Pt 2):1 158-1 167. doi: 10.1016/0002-8703(85)90702-1

35. Singh BN, Thoden WR, Wahl J. Acebutolol: a 
review of its pharmacology, pharmacokinetics, clinical uses, and adverse effects. Pharmacother J Hum Pharmacol Drug Ther. 1986;6(2):45-61. doi: 10.1002/j.1875-91 14.1986.tb03451.x

36. Abdelkrim MA, Martignat L, Gogny M, Desfontis JC, Noireaud J, Mallem MY. Celiprolol induces $\beta$ 3-adrenoceptors-dependent relaxation in isolated porcine coronary arteries. Can J Physiol Pharmacol. 2013;91 (10):791-796. doi: 10.1139/cjpp-2013-0091

37. Nawarskas JJ, Cheng-Lai A, Frishman WH. Celiprolol: A unique selective adrenoceptor modulator. Cardiol Rev. 2017;25(5):247-253. doi: 10.1097/CRD.000 0000000000159

38. Milne RJ, Buckley MM. Celiprolol. An updated review of its pharmacodynamic and pharmacokinetic properties, and therapeutic efficacy in cardiovascular disease. Drugs. 1991;41:941-969. doi: 10.2165/00003495-199141060-00009

39. Clauzel AM, Jean T, Etienne R, Visier S, Michel F. Effect of long-term treatment with celiprolol on pulmonary function in a group of mild hypertensive asthmatics. J Int Med Res. 1988;16:27-33.

40. Lombard JN, Bonnotte B, Maynadie M, Foucher $P$, Degat OR, Jeannin L, et al. Celiprolol pneumonitis. Eur Respir J. 1993;6(4):588-591.

41. Shand DG. Pharmacokinetic properties of the beta-adrenergic receptor blocking drugs. Drugs. 1974;7(1):39-47. doi: 10.2165/00003495-19740701 $0-00003$

42. Geyskes GG, Stutterheim A, Boer P, Mees EJ. Comparison of the antihypertensive effect of propranolol and practolol combined with chlorthalidone. Eur J Clin Pharmacol. 1975;9(2-3):85-90. doi: 10.1007/BFO 0614001

43. Garylarde PM, Sarkany I. Side effects of practolol. Br Med J. 1975;3(5980):435. doi: 10.1136/bmj.3.59 80.435-a

44. Kennedy I, Levy GP. Combined alpha- and beta-adrenoceptor blocking drug AH 5158: further studies on alpha adrenoceptor blockade in anaesthetized animals. Br J Pharmacol. 1975; 53(4):585592. doi: 10.1111/j.1476-5381.1975.tb07398.x

45. MacCarthy EP, Bloomfield SS. Labetalol: a review of its pharmacology, pharmacokinetics, clinical uses and adverse effects. Pharmacother J Hum Pharmacol Drug Ther. 1983;3(4):193-217. doi: 10.1002/j.1875-91 14.1983.tb03252.x

46. Cannon CM, Levy $P$, Baumann BM, Borczuk $P$, Chandra A, Cline DM, et al. Intravenous nicardipine and labetalol use in hypertensive patients with signs or symptoms suggestive of end-organ damage in the emergency department: a subgroup analysis of the CLUE trial. BMJ open. 2013;3(3):1-7. doi: 10.1136/bmjopen-2012-002338

47. Webster LM, Myers JE, Nelson-Piercy C, Harding K, Cruickshank JK, Watt-Coote I, et al. Labetalol versus nifedipine as antihypertensive treatment for chronic hypertension in pregnancy: a randomized controlled trial. Hypertens. 2017;70(5):915-922. doi: 10.1161/HYPERTENSIONAHA. 117.09972

48. Zublena F, De Gennaro C, Corletto F. Retrospective evaluation of labetalol as antihypertensive agent in dogs. BMC Vet Res. 2020;16(1):1-8. doi: 10.1186/s12917-020-02475-4

49. Kane J, Gregg I, Richards DA. Double-blind trial of labetalol. Br J Clin Pharmacol. 1976:3/4 Suppl 3):737-741.

50. Waal-Manning $\mathrm{HJ}$, Simpson FO. Review of long-term treatment with labetalol. $\mathrm{Br} \mathrm{J}$ Clin Pharmacol. 1982;13(S1):65S-73. doi: 10.1111/j.1365-2125. 1982.tb01891.x

51. Ruffolo RR, Feuerstein GZ. Pharmacology of carvedilol: rationale for use in hypertension, coronary artery disease, and congestive heart failure. Cardiovasc Drugs Ther. 1997;11(1):247-256. doi: 10.1023/a:100773 5729121

52. Meyer-Sabellek W, Schulte KL, Streitberg B, Gotzen R. Two-year follow-up of 24-hour indirect blood pressure monitoring: an open study. Drugs. 1988;36(6):106-1 12. doi: 10.2165/00003495-19880036 6-00018

53. Messerli FH, Grossman E. $\beta$-blockers in hypertension: is carvedilol different? Am J Cardiol. 2004;93(9) :7-12.

54. Krämer BK, Ress KM, Erley CM, Risler T. Pharmacokinetic and blood pressure effects of carvedilol in patients with chronic renal failure. Eur J Clin Pharmacol. 1992;43(1):85-88. doi: 10.1007/BF02280760

55. Fongemie J, Felix-Getzik E. A review of nebivolol pharmacology and clinical evidence. Drugs. 2015;75(12):1349-1371. doi: 10.1007/s40265-0150435-5

56. Greathouse M. Nebivolol efficacy and safety in patients with stage I-Il hypertension. Clin Cardiol. 2010;33(4):20-27. doi: 10.1002/clc.20508

57. Ceron CS, Rizzi E, Guimarães DA, Martins-Oliveira A, Gerlach RF, Tanus-Santos JE. Nebivolol attenuates prooxidant and profibrotic mechanisms involving TGF- $\beta$ and MMPs, and decreases vascular remodeling in renovascular hypertension. Free Radic Biol. Med 2013; 65: 47-56. doi: 10.1016/j.freeradbiomed.2013.06.033

58. John C. A review of the safety and efficacy of nebivolol in the mildly hypertensive patient. Vasc Health Risk Manag. 2007; 3(6): 909-917.

59. Coats A, Jain S. Protective effects of nebivolol from oxidative stress to prevent hypertension-related target organ damage. J Hum Hypertens. 2017;31 (6):376-381. doi: 10.1038/jhh.2017.8

60. Shin J, Choi YJ, Hong GR, Jeon DW, Kim DH, Koh $Y Y$, et al. Real-world efficacy and safety of nebivolol in Korean patients with hypertension from the BENEFIT KOREA study. J Hypertens. 2020;38(3):527-535. doi: 10.1097/HJH.000000000000229. 